\title{
molecules
}

ISSN 1420-3049

www.mdpi.com/journal/molecules

Article

\section{In Vitro Anti-Candida Activity of Certain New 3-(1H-Imidazol-1-yl)propan-1-one Oxime Esters}

\author{
Mohamed I. Attia ${ }^{1,2, *}$, Azza S. Zakaria ${ }^{3,4}$, Maha S. Almutairi ${ }^{1}$ and Soraya W. Ghoneim ${ }^{1}$ \\ 1 Department of Pharmaceutical Chemistry, College of Pharmacy, King Saud University, Riyadh 11451, \\ Saudi Arabia \\ 2 Medicinal and Pharmaceutical Chemistry Department, Pharmaceutical and Drug Industries \\ Research Division, National Research Centre, Dokki, Giza 12622, Egypt \\ 3 Department of Pharmaceutics, College of Pharmacy, King Saud University, Riyadh 11451, \\ Saudi Arabia \\ 4 Department of Microbiology, Faculty of Pharmacy, Alexandria University, Alexandria 21500, \\ Egypt
}

* Author to whom correspondence should be addressed; E-Mail: mattia@ksu.edu.sa.

Received: 1 September 2013; in revised form: 19 September 2013 / Accepted: 23 September 2013 / Published: 30 September 2013

\begin{abstract}
Anti-Candida activities of certain new oximes $\mathbf{4 a - d}$ and their respective aromatic esters $\mathbf{5 a}-\mathbf{l}$ are reported. The tested compounds $\mathbf{4 a - d}$ and $\mathbf{5 a}-\mathbf{l}$ exhibited better anti-Candida profiles than fluconazole. Compound 5j, namely (E)-3-(1H-imidazol-1-yl)-1phenylpropan-1-one $O$-4-chlorobenzoyl oxime emerged as the most active congener, with a MIC value of $0.0054 \mu \mathrm{mol} / \mathrm{mL}$ being more potent than both fluconazole $(\mathrm{MIC}>1.6325 \mu \mathrm{mol} / \mathrm{mL})$ and miconazole $(\mathrm{MIC}$ value $=0.0188 \mu \mathrm{mol} / \mathrm{mL})$ as a new anti-Candida albicans agent.
\end{abstract}

Keywords: synthesis; Mannich reaction; azoles; oxime esters; anti-Candida

\section{Introduction}

Fungal infections have recently emerged as a growing threat to human health, especially in patients with weakened or compromised immune systems [1,2]. The organisms most often responsible for invasive fungal infection are Candida and Aspergillus species [3]. Candida infections are adverse in their manifestations, varying from superficial skin problems, chronic infection of the nails, mouth, 
throat or vagina to frequently fatal systemic diseases that involve the lungs, heart, gastrointestinal tract, central nervous system and other organs [4]. These infections are considered to be opportunistic in nature, since some aspect of the host's defense system is impaired in some way. In spite of the large number of the available antifungal agents, the medical need is still largely unmet and therefore, efforts to discover new antifungal agents are a must. This is largely due to the perceived threat of emerging new pathogenic fungi and resistance of many strains to existing therapy [5-7].

Five major classes of the clinically used antifungal drugs are available, namely polyenes (such as amphotericin B and nystatin), echinocandins (such as caspofungin), allylamines (such as naftifine and terbinafine), fluoropyrimidines (such as 5-fluorocytosine) and azoles (such as miconazole, fluconazole and oxiconazole) (Figure 1) [8-10]. Azole antifungal drugs remain the mainstay of therapy for candidal life-threatening fungal infections due to their safety profile and high therapeutic index [11]. The mechanism of action of azole antifungals relies on their ability to inhibit Cyt-P450 dependent sterol $14 \alpha$-demethylase through binding to the heme cofactor of the cytochrome CYP51 leading to inhibition of sterols synthesis in fungi [4,12].

Figure 1. Azole antifungal agents used in clinical therapy.<smiles>[R]c1cc(Cl)ccc1COC(Cn1ccnc1)c1ccc(Cl)cc1Cl</smiles>

$\mathbf{R}=\mathbf{H}$ : Econazole

$\mathbf{R}=\mathrm{Cl}$ : Miconazole<smiles>Clc1ccc(C(Cn2ccnc2)OCc2ccsc2Cl)c(Cl)c1</smiles>

Tioconazole<smiles>Clc1ccc(/C(Cn2ccnc2)=N\OCc2ccc(Cl)cc2Cl)cc1</smiles>

Oxiconazole<smiles>OC(Cn1cncn1)(Cn1cncn1)c1ccc(F)cc1F</smiles>

Fluconazole<smiles>Clc1ccccc1C(c1ccccc1)(c1ccccc1)n1ccnc1</smiles>

Clotrimazole<smiles>Nc1nc(=O)[nH]cc1F</smiles>

5-Flucytosine

An evaluation of the literature exposed that some potent clinically used azole antifungals are derived from oxime-containing scaffolds [13]. Additionally, most of the available imidazole-containing antifungal agents have a two carbon atom spacer between the imidazole pharmacophore and an aromatic moiety, whereas limited information is available about imidazole-containing antifungals having a three-carbon atom linker between the imidazole pharmacophore and the aromatic moiety [14,15]. Moreover, Walker et al. reported that some aryl and aralkyl esters of 2-(1H-imidazol-1-yl)-1-phenylethanols displayed more anti-Candida albicans activity than miconazole [16]. 
Based upon the aforementioned premises, we became interested in the development of new imidazole-containing drug-like anti-Candida agents incorporating oxime functionality, exemplified by compounds $\mathbf{4 a - d}$ as well as their respective aromatic esters, compounds $\mathbf{5 a}-\mathbf{l}$.

\section{Results and Discussion}

\subsection{Chemistry}

The pivotal ketones 3a-d were prepared using the synthetic strategy outlined in Scheme 1. Thus, the appropriate acetophenone 1a-d was reacted with dimethylamine hydrochloride and paraformaldehyde in the presence of a catalytic amount of concentrated hydrochloric acid to yield Mannich base hydrochlorides $\mathbf{2 a - d}$. Imidazole was alkylated with the appropriate Mannich base $\mathbf{2 a - d}$ to give ketones 3a-d in good yields (Scheme 1).

Scheme 1. Synthesis of the ketones 3a-d.

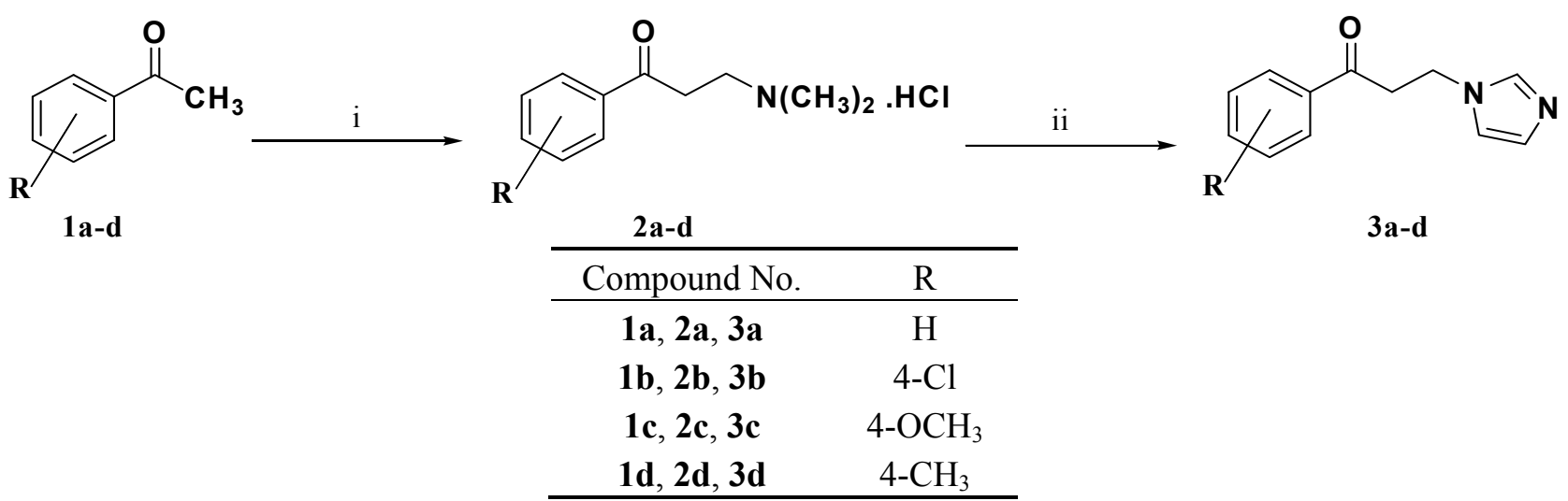

Reagents and conditions: (i) $\mathrm{HN}\left(\mathrm{CH}_{3}\right)_{2} \cdot \mathrm{HCl},\left(\mathrm{CH}_{2} \mathrm{O}\right)_{\mathrm{n}}$, conc. $\mathrm{HCl}$, ethanol, reflux, $2 \mathrm{~h}$; (ii) imidazole, water, reflux, $5 \mathrm{~h}$.

Ketones 3a-d were allowed to react with hydroxylamine hydrochloride in the presence of potassium hydroxide to yield oximes $\mathbf{4 a - d}$. X-ray crystallography is a decisive analytical tool which can confirm the configuration of the produced oximes 4a-d. Accordingly, the assigned (E)-configuration of compounds $\mathbf{4 a - d}$ was established via single crystal X-ray structure of the oxime 4a (Figure 2) [17].

The produced oximes $\mathbf{4 a - d}$ were subjected to esterification with the appropriate carboxylic acid derivatives using ethyl-3-(3-dimethylaminopropyl)carbodiimide hydrochloride (EDCI.HCl) in the presence of 4-dimethylaminopyridine (DMAP) to yield the target compounds 5a-l (Scheme 2). The chemical structures of oximes $\mathbf{4 a}-\mathbf{d}$ and the title compounds $\mathbf{5 a}-\mathbf{l}$ were confirmed via $\mathrm{IR},{ }^{1} \mathrm{H}-\mathrm{NMR}$, ${ }^{13} \mathrm{C}-\mathrm{NMR}$ and mass spectral data. 
Figure 2. ORTEP diagram of the title compound $4 \mathbf{a}$ drawn at $50 \%$ ellipsoids for non-hydrogen atoms.

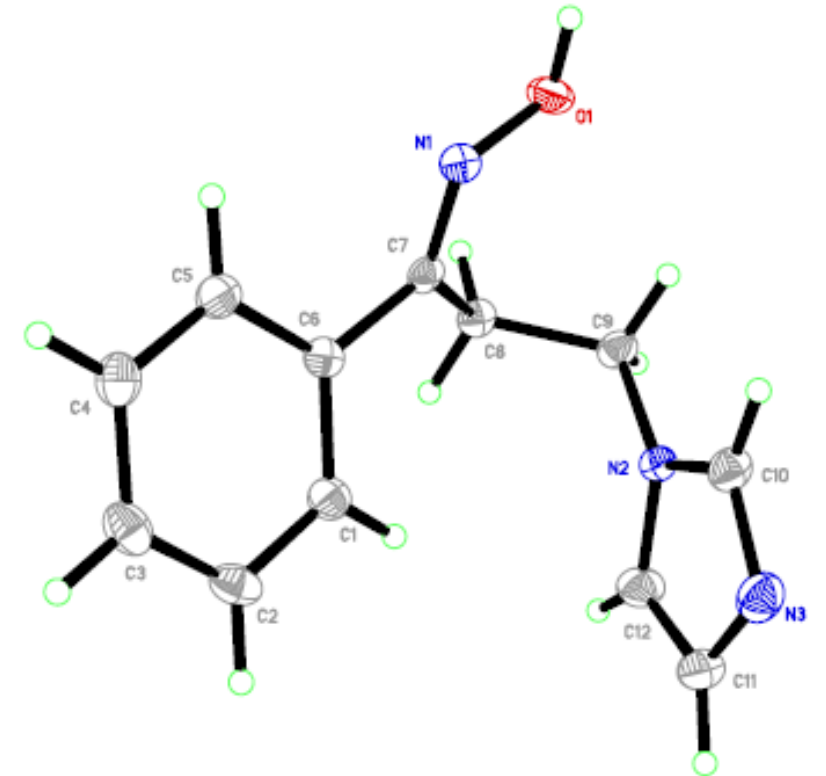

Scheme 2. Synthesis of the target compounds $\mathbf{5 a}-\mathbf{l}$.

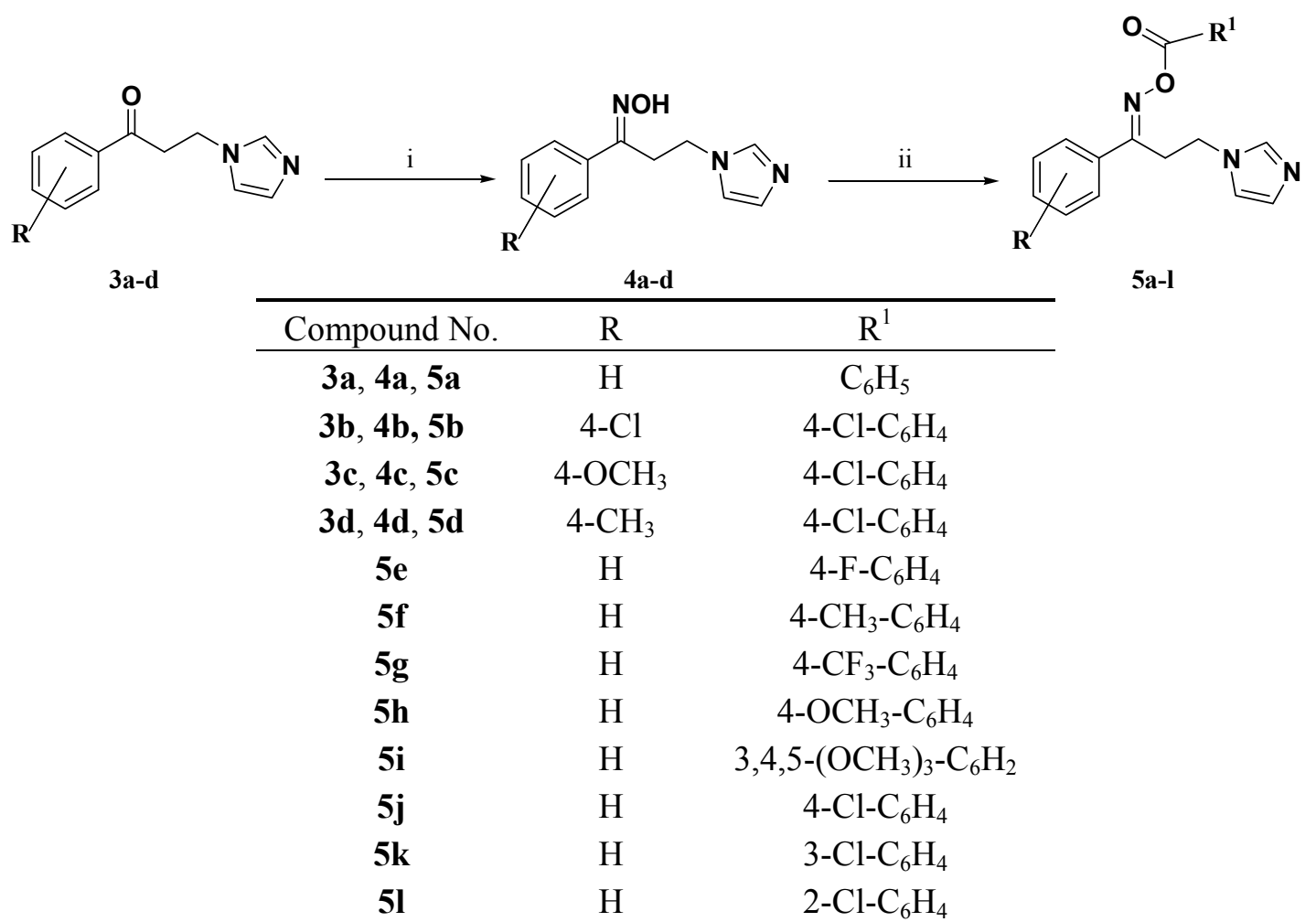

Reagents and conditions: (i) $\mathrm{H}_{2} \mathrm{NOH} \cdot \mathrm{HCl}, \mathrm{KOH}$, ethanol, reflux, $18 \mathrm{~h}$.; (ii) an appropriate carboxylic acid, EDCI·HCl, DMAP, DCM, rt, $18 \mathrm{~h}$.

\subsection{In Vitro Anti-Candida Activity and SARs}

Fluconazole is the gold standard azole antifungal and used clinically as the first line of treatment for fungal infections, especially those caused by C. albicans. However, its extensive medical use has led to 
the emergence of resistance [18]. The in vitro anti-Candida activity of the synthesized imidazole-containing oximes $\mathbf{4 a}-\mathbf{d}$ and their respective aromatic esters $\mathbf{5 a}-\mathbf{I}$ was evaluated against two clinical isolates of Candida, C. albicans and C. tropicalis, which are resistant to fluconazole (MIC $>1.6325 \mu \mathrm{mol} / \mathrm{mL}$ ). The test compounds $\mathbf{4 a -} \mathbf{d}$ and $\mathbf{5 a}-\mathbf{l}$ incorporate a three-carbon atom bridge between the imidazole pharmacophore and the aromatic moiety to gain insight about anti-Candida activity of this type of compounds. The anti-Candida activities, expressed as diameter of the inhibition zone (DIZ) and minimum inhibition concentration (MIC) for the oximes $\mathbf{4 a - d}$, the target compounds 5a-l as well as for the reference drugs fluconazole and miconazole, are summarized in Table 1.

Table 1. Anti-Candida activity of oximes $4 \mathbf{a}-\mathbf{d}$ and the target compounds $\mathbf{5 a}-\mathbf{I}$ against Candida albicans and Candida tropicalis.

\begin{tabular}{|c|c|c|c|c|}
\hline \multirow[t]{2}{*}{ Compound No } & \multicolumn{2}{|c|}{ Candida albicans } & \multicolumn{2}{|c|}{ Candida tropicalis } \\
\hline & $\mathbf{D I Z} \pm \mathbf{S D}$ * & $\mathrm{MIC}(\mu \mathrm{mol} / \mathrm{mL}) * *$ & $\mathrm{DIZ} \pm \mathrm{SD}$ * & $\operatorname{MIC}(\mu \mathrm{mol} / \mathrm{mL}) * *$ \\
\hline $4 a$ & $21 \pm 1.0$ & 0.5807 & $20 \pm 0.5$ & 0.5807 \\
\hline $4 b$ & $13 \pm 0.6$ & 0.5019 & $8 \pm 1.0$ & 0.5019 \\
\hline $4 c$ & $9 \pm 1.15$ & 0.5099 & $8 \pm 1.0$ & 0.2549 \\
\hline 4d & $8 \pm 1.0$ & 0.5456 & $8 \pm 1.0$ & 0.5456 \\
\hline $5 \mathbf{a}$ & $11 \pm 1.2$ & 0.3919 & $8 \pm 1.0$ & 0.7837 \\
\hline $5 \mathbf{b}$ & $18 \pm 1.1$ & 0.0805 & $12 \pm 1.0$ & 0.6439 \\
\hline $5 c$ & $16 \pm 0.4$ & 0.3257 & $16 \pm 1.2$ & 0.3257 \\
\hline 5d & $18 \pm 0.9$ & 0.1699 & $14 \pm 0.5$ & 0.3398 \\
\hline $5 e$ & $16 \pm 0.9$ & 0.3708 & $14 \pm 0.6$ & 0.3708 \\
\hline $5 f$ & $7 \pm 1.0$ & 0.3752 & $8 \pm 1.0$ & 0.1876 \\
\hline $5 g$ & $13 \pm 0.6$ & 0.6454 & $14 \pm 1.0$ & 0.3227 \\
\hline $5 \mathrm{~h}$ & $24 \pm 1.1$ & 0.0112 & $17 \pm 1.0$ & 0.3582 \\
\hline $5 \mathbf{i}$ & $17 \pm 1.1$ & 0.3053 & $14 \pm 0.5$ & 0.3053 \\
\hline $5 \mathbf{j}$ & $25 \pm 1.0$ & 0.0054 & $25 \pm 1.2$ & 0.1767 \\
\hline $5 \mathbf{k}$ & $20 \pm 0.9$ & 0.0221 & $14 \pm 0.5$ & 0.7069 \\
\hline 51 & $12 \pm 1.0$ & 0.7069 & $12 \pm 0.7$ & 0.3535 \\
\hline Fluconazole & $15 \pm 0.5$ & $>1.6325$ & $16 \pm 0.5$ & $>1.6325$ \\
\hline Miconazole & $38 \pm 1.1$ & 0.0188 & $24 \pm 0.5$ & 0.0024 \\
\hline
\end{tabular}

* The arithmetic mean of the inhibition zone diameters in mean \pm standard deviation in $\mathrm{mm}$. ** The lowest concentration of the compound that produced $80 \%$ microbial growth inhibition $(\mu \mathrm{mol} / \mathrm{mL})$.

The preliminary anti-Candida potential of the test compounds $\mathbf{4 a - d}$ and $\mathbf{5 a}-\mathbf{I}$ was evaluated using the DIZ assay and the results are presented in Table 1. The test compounds displayed a promising anti-Candida activity (DIZ $=7-25 \mathrm{~mm}$ ) where compound $\mathbf{5 j}$ was the most active congener (DIZ $=25 \pm 1$ and $25 \pm 1.2 \mathrm{~mm}$ against $C$. albicans and C. tropicalis, respectively).

The oxime 4a exhibited good anti-Candida activity (MIC value $=0.5807 \mu \mathrm{mol} / \mathrm{mL}$ ) toward both C. albicans and C. tropicalis, being more potent than fluconazole (MIC value $>1.6325 \mu \mathrm{mol} / \mathrm{mL}$ ) but weaker than miconazole (MIC value $=0.0188$ and $0.0024 \mu \mathrm{mol} / \mathrm{mL}$ for $C$. albicans and $C$. tropicalis, respectively). Substitution of the aromatic ring of $\mathbf{4 a}$ with substituents endowed with different electronic and steric properties like chloro, methoxy and/or methyl groups gave compounds $\mathbf{4 b}, \mathbf{4 c}$ and $\mathbf{4 d}$, 
respectively, aiming to enhance its anti-Candida activity. Unfortunately, the anti-Candida activity of $4 \mathbf{a}$ did not improve significantly, except for compound $4 \mathbf{c}$ toward $C$. tropicalis (MIC value $=0.2549 \mu \mathrm{mol} / \mathrm{mL}$ ).

De Vita et al. reported that the presence of a second aromatic ring could enhance the antifungal activity of azoles [19]. Consequently, the respective aromatic esters $\mathbf{5 a}-\mathbf{l}$ of the oximes $\mathbf{4 a - d}$ were prepared and biologically evaluated as new anti-Candida agents. Esterification of the hydroxyl group of $\mathbf{4 a}$ with benzoic acid gave compound 5a which displayed better anti-Candida activity (MIC value $=0.3919 \mu \mathrm{mol} / \mathrm{mL}$ ) than that of $4 \mathbf{a}$ toward C. albicans. Moreover, esterification of the hydroxyl group of the oximes $\mathbf{4 b}-\mathbf{d}$ with 4-chlorobenzoic acid gave the respective esters $\mathbf{5 b}$ - $\mathbf{d}$. Compounds $\mathbf{5 b}-\mathbf{d}$ showed better anti-Candida profile than their respective oximes $\mathbf{4 b} \mathbf{b}-\mathbf{d}$, where compound $\mathbf{5 b}$ is the most active congener with a MIC value of $0.0805 \mu \mathrm{mol} / \mathrm{mL}$ toward C. albicans.

Substitution of the aromatic ester functionality of $\mathbf{5 a}$ with fluoride, methyl and/or trifluoromethyl groups gave compounds $\mathbf{5 e}-\mathbf{g}$ which exhibited anti-Candida albicans activity comparable with that of 5a, except for compound $\mathbf{5 g}(\mathrm{MIC}$ value $=0.6454 \mu \mathrm{mol} / \mathrm{mL}$ ) which was weaker than 5a. Compounds $\mathbf{5 e}-\mathbf{g}$ displayed better anti-Candida tropicalis profiles than that of $\mathbf{5 a}$ where compound $\mathbf{5} \mathbf{f}$ is the most active candidate with a MIC value of $0.1876 \mu \mathrm{mol} / \mathrm{mL}$.

Substitution of the aromatic ester functionality of $\mathbf{5 a}$ with a group endowed with negative inductive effect and positive mesomeric properties like a methoxy group gave compound $\mathbf{5} \mathbf{h}$, which showed a comparable anti-Candida albicans profile (MIC value $=0.0112 \mu \mathrm{mol} / \mathrm{mL}$ ) with that of miconazole (MIC value $=0.0188 \mu \mathrm{mol} / \mathrm{mL}$ ) and was about 145 -fold more potent than fluconazole $(\mathrm{MIC}>1.6325 \mu \mathrm{mol} / \mathrm{mL}$ ). This result encouraged us to synthesize the trimethoxy analogue of 5a, compound $\mathbf{5 i}$. Unfortunately, $\mathbf{5 i}$ exhibited weaker anti-Candida albicans (MIC value $=0.3053 \mu \mathrm{mol} / \mathrm{mL}$ ) than that $\mathbf{5 h}$.

Compound $\mathbf{5 j}$ emerged as the most active congener in the whole series of synthesized compounds against both $C$. albicans and C. tropicalis. Compound $\mathbf{5 j}$, the 4-chloro analogue of $\mathbf{5 a}$, exhibited about 3.5-fold and 300-fold more potency than miconazole and the gold standard azole antifungal, fluconazole, respectively, as a drug-like anti-Candida albicans agent. The positional isomers of compound $\mathbf{5 j}$, compounds $\mathbf{5 k}$ and $\mathbf{5}$, displayed weaker anti-Candida activity than that of $\mathbf{5} \mathbf{j}$.

\section{Experimental}

\subsection{Chemistry}

\subsubsection{General}

Melting points were determined on a Gallenkamp melting point apparatus, and are uncorrected. Infrared (IR) spectra were recorded as $\mathrm{KBr}$ disks using the Perkin Elmer FT-IR Spectrum BX apparatus. NMR spectra were carried out on a Bruker NMR spectrometer operating at $500 \mathrm{MHz}$ for ${ }^{1} \mathrm{H}$ and $125.76 \mathrm{MHz}$ for ${ }^{13} \mathrm{C}$ at the Research Center, College of Pharmacy, King Saud University, Saudi Arabia. TMS was used as internal standard and chemical shift values were recorded in ppm on $\delta$ scale. The ${ }^{1} \mathrm{H}-\mathrm{NMR}$ data were represented as follows: chemical shifts, multiplicity (s. singlet, d. doublet, $\mathrm{t}$. triplet, m. multiplet, br. broad) and number of protons. The ${ }^{13} \mathrm{C}-\mathrm{NMR}$ data were represented as chemical shifts and type of carbon. Mass spectra were measured on Agilent Triple Quadrupole 6410 QQQ LC/MS with an electrospray ionization (ESI) source. Silica gel thin layer chromatography (TLC) plates from Merck (silica gel precoated aluminium plates with a $245 \mathrm{~nm}$ fluorescent indicator) were used for thin 
layer chromatography. Visualization was performed by illumination with UV light source (254 $\mathrm{nm})$. Column chromatography was carried out on silica gel $60(0.063-0.200 \mathrm{~mm})$ obtained from Merck and chloroform/methanol (9:0.5) was used as a solvent system.

\subsubsection{General Procedure for Preparation of the Ketones 3a-d}

The appropriate acetophenone $\mathbf{1 a}-\mathbf{d}(200 \mathrm{mmol})$, dimethylamine hydrochloride $(270 \mathrm{mmol})$ and paraformaldehyde $(90 \mathrm{mmol})$ were heated to reflux in absolute ethanol $(35 \mathrm{~mL})$ in the presence of catalytic amount of concentrated hydrochloric acid $(0.5 \mathrm{~mL})$. Reflux of the reaction mixture was continued under stirring for two hours, cooled and acetone $(200 \mathrm{~mL})$ was added. The formed Mannich base hydrochlorides $\mathbf{2 a}-\mathbf{d}$ were precipitated, filtered off and dried. Subsequently, compounds $\mathbf{2 a}-\mathbf{d}$ (100 mmol) were dissolved in water $(100 \mathrm{~mL})$ and imidazole $(200 \mathrm{mmol})$ was added. The reaction mixture was heated to reflux for five hours, cooled and the precipitated solids were collected by filtration to give ketones 3a-d which were pure enough to be used in the next step.

3-(1H-Imidazol-1-yl)-1-phenylpropan-1-one (3a). Synthesis of 3a was previously reported [14].

1-(4-Chlorophenyl)-3-(1H-imidazol-1-yl)propan-1-one (3b). Synthesis of $\mathbf{3 b}$ was previously reported [15].

3-(1H-Imidazol-1-yl)-1-(4-methoxyphenyl)propan-1-one (3c). Synthesis of 3c was previously reported [20].

3-(1H-Imidazol-1-yl)-1-(4-methylphenyl)propan-1-one (3d). Synthesis of 3d was previously reported [21].

\subsubsection{General Procedure for Preparation of the Oximes 4a-d}

A mixture of the appropriate ketone $\mathbf{3 a}-\mathbf{d}(10 \mathrm{mmol})$, hydroxylamine hydrochloride $(20 \mathrm{mmol})$, and $\mathrm{KOH}(20 \mathrm{mmol})$ in ethanol $(10 \mathrm{~mL})$ was heated to reflux under stirring for $18 \mathrm{~h}$. The reaction mixture was allowed to cool to room temperature and the insoluble solids were filtered off. The filtrate was concentrated under vacuum and the residue was poured onto ice-cold water $(15 \mathrm{~mL})$. The precipitated solids were collected by filtration and dried to give oximes $4 \mathbf{a}-\mathbf{d}$ which were subsequently subjected to the esterification step without any further purification.

(1E)-N-Hydroxy-3-(1H-imidazol-1-yl)-1-phenylpropan-1-imine (4a). [17] Yield 70\%; colourless solid mp. $155-157^{\circ} \mathrm{C}$ (ethanol); IR (KBr): $v\left(\mathrm{~cm}^{-1}\right) 3508(\mathrm{OH}), 3149,3002,2703,1644(\mathrm{C}=\mathrm{N}), 1600,1573$, 1221, 758; ${ }^{1} \mathrm{H}-\mathrm{NMR}\left(\mathrm{CDCl}_{3}\right): \delta 3.31\left(\mathrm{t}, J=7.1 \mathrm{~Hz}, 2 \mathrm{H},-\mathrm{CH}_{2}-\mathrm{CH}_{2}-\mathrm{N}\right), 4.28(\mathrm{t}, J=7.1 \mathrm{~Hz}, 2 \mathrm{H}$, $\left.-\mathrm{CH}_{2}-\mathrm{CH}_{2}-\mathrm{N}\right), 6.96(\mathrm{~s}, 1 \mathrm{H},-\mathrm{N}-\mathrm{CH}=\mathrm{CH}-\mathrm{N}=), 7.07$ (s, $\left.1 \mathrm{H},-\mathrm{N}-\mathrm{CH}=\mathrm{CH}-\mathrm{N}=\right), 7.29-7.49(\mathrm{~m} 5 \mathrm{H}, \mathrm{Ar}-\mathrm{H})$, $7.58(\mathrm{~s}, 1 \mathrm{H},-\mathrm{N}-\mathrm{CH}=\mathrm{N}-) ;{ }^{13} \mathrm{C}-\mathrm{NMR}\left(\mathrm{CDCl}_{3}\right): \delta 28.3\left(-\mathrm{CH}_{2}-\mathrm{CH}_{2}-\mathrm{N}\right), 41.8\left(-\mathrm{CH}_{2}-\mathrm{CH}_{2}-\mathrm{N}\right), 119.1$ $(-\mathrm{N}-\mathrm{CH}=\mathrm{CH}-\mathrm{N}=), \quad 126.1, \quad 128.8,128.9 \quad(-\mathrm{N}-\mathrm{CH}=\mathrm{CH}-\mathrm{N}=, \quad$ Ar-CH) $, 135.1,137.0$ (Ar-C), 139.5 $(-\mathrm{N}-\mathrm{CH}=\mathrm{N}-), 155.4(\mathrm{C}=\mathrm{N}-\mathrm{OH}) ; \mathrm{MS} m / z(\mathrm{ESI}): 216.0[\mathrm{M}+1]^{+}$.

(1E)-1-(4-Chlorophenyl)-N-hydroxy-3-(1H-imidazol-1-yl)propan-1-imine

(4b). The synthesis and characterization of $\mathbf{4 b}$ were previously reported [22]. 
(1E)-N-Hydroxy-3-(1H-imidazol-1-yl)-1-(4-methoxyphenyl)propan-1-imine (4c). Yield 65\%; pale yellow solid mp. $136-138^{\circ} \mathrm{C}$ (ethanol); IR (KBr): $v\left(\mathrm{~cm}^{-1}\right) 3512(\mathrm{OH}), 3135,3026,2632,1648(\mathrm{C}=\mathrm{N})$, 1680, 1566, 1228, 752; ${ }^{1} \mathrm{H}-\mathrm{NMR}\left(\mathrm{CDCl}_{3}\right): \delta 3.26\left(\mathrm{t}, J=6.5 \mathrm{~Hz}, 2 \mathrm{H},-\mathrm{CH}_{2}-\mathrm{CH}_{2}-\mathrm{N}\right), 3.83(\mathrm{~s}, 3 \mathrm{H}$, $\left.\mathrm{OCH}_{3}\right), 4.28\left(\mathrm{t}, J=7.1 \mathrm{~Hz}, 2 \mathrm{H},-\mathrm{CH}_{2}-\mathrm{CH}_{2}-\mathrm{N}\right), 6.89(\mathrm{~d}, J=7.5 \mathrm{~Hz}, 2 \mathrm{H}, \mathrm{Ar}-\mathrm{H}), 6.97(\mathrm{~s}, 1 \mathrm{H}$, $-\mathrm{N}-\mathrm{C} H=\mathrm{CH}-\mathrm{N}=), 7.08$ (s, 1H, -N-CH=CH-N=), 7.44 (d, $J=7.5 \mathrm{~Hz}, 2 \mathrm{H}, \mathrm{Ar}-\mathrm{H}), 7.58$ (s, 1H, -N-CH=N-); ${ }^{13} \mathrm{C}-\mathrm{NMR}\left(\mathrm{CDCl}_{3}\right): \delta 28.9\left(-\mathrm{CH}_{2}-\mathrm{CH}_{2}-\mathrm{N}\right), 43.6\left(-\mathrm{CH}_{2}-\mathrm{CH}_{2}-\mathrm{N}\right), 55.4\left(\mathrm{OCH}_{3}\right), 114.0(\mathrm{Ar}-\mathrm{CH}), 119.1$ $(-\mathrm{N}-\mathrm{CH}=\mathrm{CH}-\mathrm{N}=), 127.4,127.9,129.1 \quad(-\mathrm{N}-\mathrm{CH}=\mathrm{CH}-\mathrm{N}=$, Ar-CH, Ar-C), $137.1 \quad(-\mathrm{N}-\mathrm{CH}=\mathrm{N}-), 155.4$ $(\mathrm{C}=\mathrm{N}-\mathrm{OH}), 160.5$ (Ar-C); MS $m / z$ (ESI): $246.0[\mathrm{M}+1]^{+}$.

(1E)-N-Hydroxy-3-(1H-imidazol-1-yl)-1-(4-methylphenyl)propan-1-imine (4d). Yield 65\%; white solid mp. 147-149 ${ }^{\circ} \mathrm{C}$ (ethanol); IR (KBr): $v\left(\mathrm{~cm}^{-1}\right) 3509(\mathrm{OH}), 3119,2702,1639(\mathrm{C}=\mathrm{N}), 1679,1512,1230$, 738; ${ }^{1} \mathrm{H}-\mathrm{NMR}\left(\mathrm{CDCl}_{3}\right): \delta 2.27\left(\mathrm{~s}, 3 \mathrm{H}, \mathrm{CH}_{3}\right), 3.18\left(\mathrm{t}, J=7.0 \mathrm{~Hz}, 2 \mathrm{H},-\mathrm{CH}_{2}-\mathrm{CH}_{2}-\mathrm{N}\right), 4.18(\mathrm{t}, J=7.0 \mathrm{~Hz}$, $\left.2 \mathrm{H},-\mathrm{CH}_{2}-\mathrm{CH}_{2}-\mathrm{N}\right), 6.88(\mathrm{~s}, 1 \mathrm{H},-\mathrm{N}-\mathrm{CH}=\mathrm{CH}-\mathrm{N}=), 6.99(\mathrm{~s}, 1 \mathrm{H},-\mathrm{N}-\mathrm{CH}=\mathrm{CH}-\mathrm{N}=), 7.08$ (d, J = 7.8 Hz, $2 \mathrm{H}, \mathrm{Ar}-\mathrm{H}), 7.30$ (d, J=7.9 Hz, 2H, Ar-H), 7.49 (s, $1 \mathrm{H},-\mathrm{N}-\mathrm{CH}=\mathrm{N}-) ;{ }^{13} \mathrm{C}-\mathrm{NMR}\left(\mathrm{CDCl}_{3}\right): \delta 21.3\left(\mathrm{CH}_{3}\right)$, $28.9\left(-\mathrm{CH}_{2}-\mathrm{CH}_{2}-\mathrm{N}\right), 43.6\left(-\mathrm{CH}_{2}-\mathrm{CH}_{2}-\mathrm{N}\right), 119.1(-\mathrm{N}-\mathrm{CH}=\mathrm{CH}-\mathrm{N}=), 125.9,129.1,129.4(-\mathrm{N}-\mathrm{CH}=C \mathrm{H}-\mathrm{N}=$, Ar-CH), 132.6, 137.1, 139.4 (-N-CH=N-, Ar-C), 154.7 (C=N-OH); MS m/z (ESI): $230.0[\mathrm{M}+1]^{+}$.

\subsubsection{General Procedure for the Synthesis of the Target Oxime Esters 5a-I}

A solution of the appropriate carboxylic acid $(7 \mathrm{mmol})$ and $\mathrm{EDCI} \cdot \mathrm{HCl}(7.3 \mathrm{mmol})$ was stirred in $\operatorname{DCM}(75 \mathrm{~mL})$ in the presence of DMAP $(400 \mathrm{mg})$. The appropriate oxime $4 \mathbf{a}-\mathbf{d}(6.9 \mathrm{mmol})$ was added to the stirred reaction mixture and stirring was continued for further $18 \mathrm{~h}$ at room temperature. The reaction mixture was washed successively with water $(2 \times 20 \mathrm{~mL}), 10 \% \mathrm{NaHCO}_{3}$ solution $(2 \times 15 \mathrm{~mL})$, and water $(2 \times 15 \mathrm{~mL})$. The organic layer was separated, dried $\left(\mathrm{Na}_{2} \mathrm{SO}_{4}\right)$ and evaporated under reduced pressure and the residue was purified either by recrystallisation (for solids) or by column chromatography (for oils).

(E)-3-(1H-Imidazol-1-yl)-1-phenylpropan-1-one O-benzoyl oxime (5a). Yield 41\%; colourless viscous oil; IR (KBr): $v\left(\mathrm{~cm}^{-1}\right)$ 3115, 2943, $1746(\mathrm{C}=\mathrm{O}), 1650(\mathrm{C}=\mathrm{N}), 1510,1243,735 ;{ }^{1} \mathrm{H}-\mathrm{NMR}\left(\mathrm{CDCl}_{3}\right)$ : $\delta(\mathrm{ppm})=3.38\left(\mathrm{t}, J=7.1 \mathrm{~Hz}, 2 \mathrm{H},-\mathrm{CH}_{2}-\mathrm{CH}_{2}-\mathrm{N}\right), 4.21\left(\mathrm{t}, J=7.1 \mathrm{~Hz}, 2 \mathrm{H},-\mathrm{CH}_{2}-\mathrm{CH}_{2}-\mathrm{N}\right), 6.84(\mathrm{~s}, 1 \mathrm{H}$, $-\mathrm{N}-\mathrm{CH}=\mathrm{CH}-\mathrm{N}=), 6.95(\mathrm{~s}, 1 \mathrm{H},-\mathrm{N}-\mathrm{CH}=\mathrm{CH}-\mathrm{N}=)$, 7.36-7.46 (m, 6H, -N-CH=N-, Ar-H), 7.55-7.60 (m, 2H, $\mathrm{Ar}-\mathrm{H}), 7.96(\mathrm{~d}, J=7.6 \mathrm{~Hz}, 2 \mathrm{H}, \mathrm{Ar}-\mathrm{H}) ;{ }^{13} \mathrm{C}-\mathrm{NMR}\left(\mathrm{CDCl}_{3}\right): \delta 31.0\left(-\mathrm{CH}_{2}-\mathrm{CH}_{2}-\mathrm{N}\right), 43.7\left(-\mathrm{CH}_{2}-\mathrm{CH}_{2}-\mathrm{N}\right)$, $118.8(-\mathrm{N}-\mathrm{CH}=\mathrm{CH}-\mathrm{N}=), 127.3,128.6,128.8,129.1,129.6,130.0,131.3(-\mathrm{N}-\mathrm{CH}=\mathrm{CH}-\mathrm{N}=, \mathrm{Ar}-\mathrm{CH}$, Ar-C), 133.0, 133.8, $136.9(-\mathrm{N}-\mathrm{CH}=\mathrm{N}-, \mathrm{Ar}-\mathrm{CH}, \mathrm{Ar}-\mathrm{C}), 163.4(\mathrm{C}=\mathrm{N}), 163.5(\mathrm{C}=\mathrm{O})$; $\mathrm{MS} \mathrm{m} / z(\mathrm{ESI})$ : $320.1[\mathrm{M}+1]^{+}$.

(E)-1-(4-Chlorophenyl)-3-(1H-imidazol-1-yl)propan-1-one O-4-chlorobenzoyl oxime (5b). Yield 56\%; white solid mp. $132-134{ }^{\circ} \mathrm{C}$ (isopropanol); IR (KBr): $v\left(\mathrm{~cm}^{-1}\right)$ 3107, $1744(\mathrm{C}=\mathrm{O}), 1650(\mathrm{C}=\mathrm{N}), 1560$, $1513,1261,748 ;{ }^{1} \mathrm{H}-\mathrm{NMR}\left(\mathrm{CDCl}_{3}\right): \delta(\mathrm{ppm})=3.43\left(\mathrm{t}, J=6.9 \mathrm{~Hz}, 2 \mathrm{H},-\mathrm{CH}_{2}-\mathrm{CH}_{2}-\mathrm{N}\right), 4.29(\mathrm{t}, J=6.9 \mathrm{~Hz}$, $\left.2 \mathrm{H},-\mathrm{CH}_{2}-\mathrm{CH}_{2}-\mathrm{N}\right), 6.89$ (s, $\left.1 \mathrm{H},-\mathrm{N}-\mathrm{CH}=\mathrm{CH}-\mathrm{N}=\right), 7.02(\mathrm{~s}, 1 \mathrm{H},-\mathrm{N}-\mathrm{CH}=\mathrm{CH}-\mathrm{N}=), 7.41$ (d, J = 8.5 Hz, 2H, Ar-H), 7.49-7.51 (m, 3H, -N-CH=N-, Ar-H), 7.60 (d, J=8.5 Hz, 2H, Ar-H), 7.94 (d, J=8.5 Hz, $2 \mathrm{H}, \mathrm{Ar}-\mathrm{H}) ;{ }^{13} \mathrm{C}-\mathrm{NMR}\left(\mathrm{CDCl}_{3}\right): \delta 30.8\left(-\mathrm{CH}_{2}-\mathrm{CH}_{2}-\mathrm{N}\right), 43.7\left(-\mathrm{CH}_{2}-\mathrm{CH}_{2}-\mathrm{N}\right), 118.8(-\mathrm{N}-\mathrm{CH}=\mathrm{CH}-\mathrm{N}=)$, 
126.9, 128.5, 129.2, 129.4, 130.0, 130.9, 131.2, (-N-CH=CH-N=, Ar-CH, Ar-C), 136.9, 137.8, 140.4 $\left(-\mathrm{N}-\mathrm{CH}=\mathrm{N}-\right.$, Ar-C), $162.5(\mathrm{C}=\mathrm{N}), 162.6(\mathrm{C}=\mathrm{O}) ; \mathrm{MS} m / z(\mathrm{ESI}): 388.0[\mathrm{M}]^{+}$.

(E)-3-(1H-Imidazol-1-yl)-1-(4-methoxyphenyl)propan-1-one O-4-chlorobenzoyl oxime (5c). Yield 70\%; white solid mp. $131-133{ }^{\circ} \mathrm{C}$ (isopropanol); IR (KBr): $v\left(\mathrm{~cm}^{-1}\right) 3123,2366,1758(\mathrm{C}=\mathrm{O}), 1684$ $(\mathrm{C}=\mathrm{N}), 1564,1514,1252,747 ;{ }^{1} \mathrm{H}-\mathrm{NMR}\left(\mathrm{CDCl}_{3}\right): \delta(\mathrm{ppm})=3.44\left(\mathrm{t}, J=6.9 \mathrm{~Hz}, 2 \mathrm{H},-\mathrm{CH}_{2}-\mathrm{CH}_{2}-\mathrm{N}\right)$, $3.87\left(\mathrm{OCH}_{3}\right), 4.32$ (t, $\left.J=7.0 \mathrm{~Hz}, 2 \mathrm{H},-\mathrm{CH}_{2}-\mathrm{CH}_{2}-\mathrm{N}\right), 6.92(\mathrm{~s}, 1 \mathrm{H},-\mathrm{N}-\mathrm{CH}=\mathrm{CH}-\mathrm{N}=), 6.96$ (d, $J=8.8 \mathrm{~Hz}$, 2H, Ar-H), 7.09 (s, 1H, -N-CH=CH-N=), 7.49 (d, $J=8.6 \mathrm{~Hz}, 2 \mathrm{H}, \mathrm{Ar}-\mathrm{H}$ ), 7.67 (d, $J=9.0 \mathrm{~Hz}, 2 \mathrm{H}$, $\mathrm{Ar}-\mathrm{H}$ ), 7.77 (s, 1H, $-\mathrm{N}-\mathrm{CH}=\mathrm{N}-), 7.94(\mathrm{~d}, J=8.6 \mathrm{~Hz}, 2 \mathrm{H}, \mathrm{Ar}-\mathrm{H}) ;{ }^{13} \mathrm{C}-\mathrm{NMR}\left(\mathrm{CDCl}_{3}\right): \delta 30.5$ $\left(-\mathrm{CH}_{2}-\mathrm{CH}_{2}-\mathrm{N}\right), 44.2\left(-\mathrm{CH}_{2}-\mathrm{CH}_{2}-\mathrm{N}\right), 55.5\left(\mathrm{OCH}_{3}\right), 114.5(\mathrm{Ar}-\mathrm{CH}), 119.1(-\mathrm{N}-\mathrm{CH}=\mathrm{CH}-\mathrm{N}=), 128.5$, 128.9, 129.2, 130.9, 131.2, (-N-CH=CH-N=, Ar-CH, Ar-C), 136.8, $140.2(-\mathrm{N}-\mathrm{CH}=\mathrm{N}-$, Ar-C), 162.3, 162.8, $162.9(\mathrm{C}=\mathrm{N}, \mathrm{C}=\mathrm{O}, \operatorname{Ar}-\mathrm{C}) ; \mathrm{MS} m / z(\mathrm{ESI}): 384.2[\mathrm{M}+1]^{+}$

(E)-3-(1H-Imidazol-1-yl)-1-(4-methylphenyl)propan-1-one O-4-chlorobenzoyl oxime (5d). Yield 58\%; white solid mp. $142-144{ }^{\circ} \mathrm{C}$ (isopropanol); IR (KBr): $v\left(\mathrm{~cm}^{-1}\right) 3065,1744(\mathrm{C}=\mathrm{O}), 1654(\mathrm{C}=\mathrm{N}), 1646$, 1559, 1508, 1254, 749; ${ }^{1} \mathrm{H}-\mathrm{NMR}\left(\mathrm{CDCl}_{3}\right): \delta(\mathrm{ppm})=2.42\left(\mathrm{~s}, 3 \mathrm{H}, \mathrm{CH}_{3}\right), 3.46(\mathrm{t}, J=6.9 \mathrm{~Hz}, 2 \mathrm{H}$, $\left.-\mathrm{CH}_{2}-\mathrm{CH}_{2}-\mathrm{N}\right), 4.31\left(\mathrm{t}, J=6.9 \mathrm{~Hz}, 2 \mathrm{H},-\mathrm{CH}_{2}-\mathrm{CH}_{2}-\mathrm{N}\right), 6.91(\mathrm{~s}, 1 \mathrm{H},-\mathrm{N}-\mathrm{CH}=\mathrm{CH}-\mathrm{N}=), 7.09(\mathrm{~s}, 1 \mathrm{H}$, $-\mathrm{N}-\mathrm{CH}=\mathrm{CH}-\mathrm{N}=), 7.27$ (d, $J=7.9 \mathrm{~Hz}, 2 \mathrm{H}, \mathrm{Ar}-\mathrm{H}), 7.49$ (d, $J=8.5 \mathrm{~Hz}, 2 \mathrm{H}, \mathrm{Ar}-\mathrm{H}$ ), $7.62(\mathrm{~d}, J=8.0 \mathrm{~Hz}$, 2H, $\mathrm{Ar}-\mathrm{H}$ ), $7.79(\mathrm{~s}, 1 \mathrm{H},-\mathrm{N}-\mathrm{CH}=\mathrm{N}-), 7.94(\mathrm{~d}, J=8.5 \mathrm{~Hz}, 2 \mathrm{H}, \mathrm{Ar}-\mathrm{H}) ;{ }^{13} \mathrm{C}-\mathrm{NMR}\left(\mathrm{CDCl}_{3}\right): \delta 21.5\left(\mathrm{CH}_{3}\right)$, $30.6\left(-\mathrm{CH}_{2}-\mathrm{CH}_{2}-\mathrm{N}\right), 44.2\left(-\mathrm{CH}_{2}-\mathrm{CH}_{2}-\mathrm{N}\right), 119.1(-\mathrm{N}-\mathrm{CH}=\mathrm{CH}-\mathrm{N}=), 127.2,128.4,128.5,129.2,129.9$, 130.9, 131.2, (-N-CH=CH-N=, Ar-CH, Ar-C), 136.8, 140.2, $142.1(-\mathrm{N}-\mathrm{CH}=\mathrm{N}-$, Ar-C $), 162.7(\mathrm{C}=\mathrm{N})$, $163.3(\mathrm{C}=\mathrm{O})$; $\mathrm{MS} m / z(\mathrm{ESI}): 368.2[\mathrm{M}+1]^{+}$.

(E)-3-(1H-Imidazol-1-yl)-1-phenylpropan-1-one O-4-fluorobenzoyl oxime (5e). Yield 62\%; pale yellow solid mp. $114-116^{\circ} \mathrm{C}$ (isopropanol); IR (KBr): $v\left(\mathrm{~cm}^{-1}\right) 3115,2848,1746(\mathrm{C}=\mathrm{O}), 1660(\mathrm{C}=\mathrm{N})$, 1571, 1249, 739; ${ }^{1} \mathrm{H}-\mathrm{NMR}\left(\mathrm{CDCl}_{3}\right): \delta(\mathrm{ppm})=3.46\left(\mathrm{t}, J=7.0 \mathrm{~Hz}, 2 \mathrm{H},-\mathrm{CH}_{2}-\mathrm{CH}_{2}-\mathrm{N}\right), 4.29(\mathrm{t}, J=7.0 \mathrm{~Hz}$, $\left.2 \mathrm{H},-\mathrm{CH}_{2}-\mathrm{CH}_{2}-\mathrm{N}\right), 6.91(\mathrm{~s}, 1 \mathrm{H},-\mathrm{N}-\mathrm{CH}=\mathrm{CH}-\mathrm{N}=), 7.02(\mathrm{~s}, 1 \mathrm{H},-\mathrm{N}-\mathrm{CH}=\mathrm{CH}-\mathrm{N}=), 7.18-7.21(\mathrm{~m}, 2 \mathrm{H}$, Ar-H), 7.43-7.52 (m, 4H, -N-CH=N-, Ar-H), 7.68 (d, $J=7.4 \mathrm{~Hz}, 2 \mathrm{H}, \mathrm{Ar}-\mathrm{H}$ ), 8.03-8.05 (m, 2H, $\mathrm{Ar}-\mathrm{H}) ;{ }^{3} \mathrm{C}-\mathrm{NMR}\left(\mathrm{CDCl}_{3}\right): \delta 30.9\left(-\mathrm{CH}_{2}-\mathrm{CH}_{2}-\mathrm{N}\right), 43.8\left(-\mathrm{CH}_{2}-\mathrm{CH}_{2}-\mathrm{N}\right), 116.1(\mathrm{~d}, J=22.1 \mathrm{~Hz}, \mathrm{Ar}-\mathrm{CH})$, $118.8(-\mathrm{N}-\mathrm{CH}=\mathrm{CH}-\mathrm{N}=), 124.9,(\mathrm{~d}, J=2.6 \mathrm{~Hz}, \mathrm{Ar}-\mathrm{C}), 127.3,129.1,129.8,131.4(-\mathrm{N}-\mathrm{CH}=\mathrm{CH}-\mathrm{N}=$, $\operatorname{Ar}-\mathrm{CH}), 132.2(\mathrm{~d}, J=9.4 \mathrm{~Hz}, \mathrm{Ar}-\mathrm{CH}), 132.8,136.9(-\mathrm{N}-\mathrm{CH}=\mathrm{N}-, \mathrm{Ar}-\mathrm{C}), 162.5(\mathrm{C}=\mathrm{N}), 163.5(\mathrm{C}=\mathrm{O})$, $167.1(\mathrm{~d}, J=254.0 \mathrm{~Hz}, \mathrm{Ar}-\mathrm{C})$; MS $m / z(\mathrm{ESI}): 338.2[\mathrm{M}+1]^{+}$.

(E)-3-(1H-Imidazol-1-yl)-1-phenylpropan-1-one O-4-methylbenzoyl oxime (5f). Yield 62\%; pale yellow solid mp. $125-127^{\circ} \mathrm{C}$ (isopropanol); IR (KBr): $v\left(\mathrm{~cm}^{-1}\right) 3115,2964,1736(\mathrm{C}=\mathrm{O}), 1647(\mathrm{C}=\mathrm{N})$, 1605, 1506, 1248, 750; ${ }^{1} \mathrm{H}-\mathrm{NMR}\left(\mathrm{CDCl}_{3}\right): \delta(\mathrm{ppm})=2.37\left(\mathrm{~s}, 3 \mathrm{H}, \mathrm{CH}_{3}\right), 3.36(\mathrm{t}, 2 \mathrm{H}, J=7.1 \mathrm{~Hz}$, $\left.-\mathrm{CH}_{2}-\mathrm{CH}_{2}-\mathrm{N}\right), 4.21\left(\mathrm{t}, 2 \mathrm{H}, J=7.0 \mathrm{~Hz}-\mathrm{CH}_{2}-\mathrm{CH}_{2}-\mathrm{N}\right), 6.84(\mathrm{~s}, 1 \mathrm{H},-\mathrm{N}-\mathrm{CH}=\mathrm{CH}-\mathrm{N}=), 6.94(\mathrm{~s}, 1 \mathrm{H}$, $-\mathrm{N}-\mathrm{CH}=\mathrm{CH}-\mathrm{N}=), 7.23(\mathrm{~d}, J=7.8 \mathrm{~Hz}, 2 \mathrm{H}, \mathrm{Ar}-\mathrm{H}), 7.35-7.41(\mathrm{~m}, 4 \mathrm{H},-\mathrm{N}-\mathrm{CH}=\mathrm{N}-, \mathrm{Ar}-\mathrm{H}), 7.59(\mathrm{~d}, J=7.0$ $\mathrm{Hz}, 2 \mathrm{H}, \mathrm{Ar}-\mathrm{H}), 7.85(\mathrm{~d}, J=8.0 \mathrm{~Hz}, 2 \mathrm{H}, \mathrm{Ar}-\mathrm{H}) ;{ }^{13} \mathrm{C}-\mathrm{NMR}\left(\mathrm{CDCl}_{3}\right): \delta 21.8\left(\mathrm{CH}_{3}\right), 31.1\left(-\mathrm{CH}_{2}-\mathrm{CH}_{2}-\mathrm{N}\right)$, $43.7\left(-\mathrm{CH}_{2}-\mathrm{CH}_{2}-\mathrm{N}\right), 118.8(-\mathrm{N}-\mathrm{CH}=\mathrm{CH}-\mathrm{N}=), 125.8,127.2,129.0,129.5,129.6,130.1,131.2,133.1$ $(-\mathrm{N}-\mathrm{CH}=\mathrm{CH}-\mathrm{N}=$, Ar-CH, Ar-C), $136.9(-\mathrm{N}-\mathrm{CH}=\mathrm{N}-), 144.7(\mathrm{Ar}-\mathrm{C}), 163.2(\mathrm{C}=\mathrm{N}), 163.5(\mathrm{C}=\mathrm{O}) ; \mathrm{MS} m / z$ (ESI): $334.0[\mathrm{M}+1]^{+}$. 
(E)-3-(1H-Imidazol-1-yl)-1-phenylpropan-1-one O-4-(trifluoromethyl)benzoyl oxime (5g). Yield 39\%; white solid mp. $125-127{ }^{\circ} \mathrm{C}$ (isopropanol); IR (KBr): $v\left(\mathrm{~cm}^{-1}\right)$ 3050, 2360, $1750(\mathrm{C}=\mathrm{O}), 1653(\mathrm{C}=\mathrm{N})$, $1559,1507,1264,737 ;{ }^{1} \mathrm{H}-\mathrm{NMR}\left(\mathrm{CDCl}_{3}\right): \delta(\mathrm{ppm})=3.47-3.49\left(\mathrm{~m}, 2 \mathrm{H},-\mathrm{CH}_{2}-\mathrm{CH}_{2}-\mathrm{N}\right), 4.29-4.32(\mathrm{~m}$, $\left.2 \mathrm{H},-\mathrm{CH}_{2}-\mathrm{CH}_{2}-\mathrm{N}\right), 6.91(\mathrm{~s}, 1 \mathrm{H},-\mathrm{N}-\mathrm{CH}=\mathrm{CH}-\mathrm{N}=), 7.05(\mathrm{~s}, 1 \mathrm{H},-\mathrm{N}-\mathrm{CH}=\mathrm{CH}-\mathrm{N}=), 7.36-7.55(\mathrm{~m}, 4 \mathrm{H}$, -N-CH=N-, Ar-H), 7.71-7.72 (m, 2H, Ar-H), 7.79 (d, J=8.0 Hz, 2H, Ar-H.), 8.13 (d, J=8.0 Hz, 2H, $\mathrm{Ar}-\mathrm{H}) ;{ }^{13} \mathrm{C}-\mathrm{NMR}\left(\mathrm{CDCl}_{3}\right): \delta 30.8\left(-\mathrm{CH}_{2}-\mathrm{CH}_{2}-\mathrm{N}\right), 43.8\left(-\mathrm{CH}_{2}-\mathrm{CH}_{2}-\mathrm{N}\right), 118.8(-\mathrm{N}-\mathrm{CH}=\mathrm{CH}-\mathrm{N}=), 125.8$ $\left(\mathrm{d}, J=3.4 \mathrm{~Hz}, C F_{3}\right), 125.9,127.3,128.6,129.2,129.8,130.0,131.6,132.6(-\mathrm{N}-\mathrm{CH}=\mathrm{CH}-\mathrm{N}=$, Ar-CH, Ar-C), 135.6, $136.9\left(-\mathrm{N}-\mathrm{CH}=\mathrm{N}-\right.$, Ar-C), $162.4(\mathrm{C}=\mathrm{N}), 164.0(\mathrm{C}=\mathrm{O}) ; \mathrm{MS} m / z(\mathrm{ESI}): 388.1[\mathrm{M}+1]^{+}$.

(E)-3-(1H-Imidazol-1-yl)-1-phenylpropan-1-one O-4-methoxybenzoyl oxime (5h). Yield 40\%; off white solid mp. $108-110{ }^{\circ} \mathrm{C}$ (isopropanol); IR (KBr): $v\left(\mathrm{~cm}^{-1}\right) 3117,2968,1735(\mathrm{C}=\mathrm{O}), 1650(\mathrm{C}=\mathrm{N})$, 1602, 1507, 1248, 765; ${ }^{1} \mathrm{H}-\mathrm{NMR}\left(\mathrm{CDCl}_{3}\right): \delta(\mathrm{ppm})=3.46\left(\mathrm{t}, J=6.9 \mathrm{~Hz}, 2 \mathrm{H},-\mathrm{CH}_{2}-\mathrm{CH}_{2}-\mathrm{N}\right), 3.91(\mathrm{~s}$, $\left.3 \mathrm{H}, \mathrm{OCH}_{3}\right), 4.30\left(\mathrm{t}, J=6.9 \mathrm{~Hz}, 2 \mathrm{H},-\mathrm{CH}_{2}-\mathrm{CH}_{2}-\mathrm{N}\right), 6.94(\mathrm{~s}, 1 \mathrm{H},-\mathrm{N}-\mathrm{CH}=\mathrm{CH}-\mathrm{N}=), 7.01(\mathrm{~d}, J=8.8 \mathrm{~Hz}$, 2H, Ar-H), $7.10(\mathrm{~s}, 1 \mathrm{H},-\mathrm{N}-\mathrm{CH}=\mathrm{CH}-\mathrm{N}=), 7.45-7.50(\mathrm{~m}, 4 \mathrm{H},-\mathrm{N}-\mathrm{CH}=\mathrm{N}-, \mathrm{Ar}-\mathrm{H}), 7.67$ (d, J= 7.0 Hz, 2H, Ar-H.), 8.01 (d, $J=8.8 \mathrm{~Hz}, 2 \mathrm{H}, \mathrm{Ar}-\mathrm{H}) ;{ }^{13} \mathrm{C}-\mathrm{NMR}\left(\mathrm{CDCl}_{3}\right): \delta 31.0\left(-\mathrm{CH}_{2}-\mathrm{CH}_{2}-\mathrm{N}\right), 43.7$ $\left(-\mathrm{CH}_{2}-\mathrm{CH}_{2}-\mathrm{N}\right), 55.6\left(\mathrm{OCH}_{3}\right), 114.1(\mathrm{Ar}-\mathrm{CH}), 118.8(-\mathrm{N}-\mathrm{CH}=\mathrm{CH}-\mathrm{N}=), 120.7,127.2,129.0,130.0$, 131.2, 131.7, $133.1(-\mathrm{N}-\mathrm{CH}=\mathrm{CH}-\mathrm{N}=, \mathrm{Ar}-\mathrm{CH}, \mathrm{Ar}-\mathrm{C}), 136.9(-\mathrm{N}-\mathrm{CH}=\mathrm{N}-), 162.9(\mathrm{C}=\mathrm{N}), 163.2(\operatorname{Ar}-\mathrm{C})$, $164.0(\mathrm{C}=\mathrm{O})$; $\mathrm{MS} m / z(\mathrm{ESI}): 350.0[\mathrm{M}+1]^{+}$.

(E)-3-(1H-Imidazol-1-yl)-1-phenylpropan-1-one O-3,4,5-trimethoxybenzoyl oxime (5i). Yield 53\%; white solid mp. $135-137{ }^{\circ} \mathrm{C}$ (isopropanol); IR (KBr): $v\left(\mathrm{~cm}^{-1}\right)$ 3103, 2938, $1742(\mathrm{C}=\mathrm{O}), 1645(\mathrm{C}=\mathrm{N})$, 1593, 1503, 1231, 749; ${ }^{1} \mathrm{H}-\mathrm{NMR}\left(\mathrm{CDCl}_{3}\right): \delta(\mathrm{ppm})=3.45\left(\mathrm{t}, \mathrm{J}=6.8 \mathrm{~Hz}, 2 \mathrm{H},-\mathrm{CH}_{2}-\mathrm{CH}_{2}-\mathrm{N}\right), 3.92$ $\left(\mathrm{s}, 6 \mathrm{H}, 2 \times \mathrm{OCH}_{3}\right), 3.94\left(\mathrm{~s}, 3 \mathrm{H}, \mathrm{OCH}_{3}\right), 4.28\left(\mathrm{t}, J=6.8 \mathrm{~Hz}, 2 \mathrm{H},-\mathrm{CH}_{2}-\mathrm{CH}_{2}-\mathrm{N}\right), 6.91(\mathrm{~s}, 1 \mathrm{H},-\mathrm{N}-\mathrm{CH}=\mathrm{CH}-\mathrm{N}=)$, $7.02(\mathrm{~s}, 1 \mathrm{H},-\mathrm{N}-\mathrm{CH}=\mathrm{CH}-\mathrm{N}=), 7.27-7.50(\mathrm{~m}, 6 \mathrm{H},-\mathrm{N}-\mathrm{CH}=\mathrm{N}-, \mathrm{Ar}-\mathrm{H}), 7.67(\mathrm{~d}, J=7.0 \mathrm{~Hz}, 2 \mathrm{H}, \mathrm{Ar}-\mathrm{H})$; ${ }^{13} \mathrm{C}-\mathrm{NMR}\left(\mathrm{CDCl}_{3}\right)$ : $\delta 30.9\left(-\mathrm{CH}_{2}-\mathrm{CH}_{2}-\mathrm{N}\right), 43.6\left(-\mathrm{CH}_{2}-\mathrm{CH}_{2}-\mathrm{N}\right), 56.5\left(2 \times \mathrm{OCH}_{3}\right), 61.0\left(\mathrm{OCH}_{3}\right), 106.9$ $(\mathrm{Ar}-\mathrm{CH}), 118.6(-\mathrm{N}-\mathrm{CH}=\mathrm{CH}-\mathrm{N}=), 123.5,127.3,129.1,130.1,131.3,132.9(-\mathrm{N}-\mathrm{CH}=\mathrm{CH}-\mathrm{N}=$, Ar-CH, Ar-C), $136.8(-\mathrm{N}-\mathrm{CH}=\mathrm{N}-), 142.9,153.2(\mathrm{Ar}-\mathrm{C}), 163.2(\mathrm{C}=\mathrm{N}), 163.6(\mathrm{C}=\mathrm{O}) ; \mathrm{MS} m / z(\mathrm{ESI}): 410.1[\mathrm{M}+1]^{+}$.

(E)-3-(1H-Imidazol-1-yl)-1-phenylpropan-1-one O-4-chlorobenzoyl oxime (5j). Yield 54\%; colourless crystals mp. $126-128{ }^{\circ} \mathrm{C}$ (isopropanol); IR (KBr): $v\left(\mathrm{~cm}^{-1}\right) 3115,2970,1743(\mathrm{C}=\mathrm{O}), 1648(\mathrm{C}=\mathrm{N})$, $1508,1249,736 ;{ }^{1} \mathrm{H}-\mathrm{NMR}\left(\mathrm{CDCl}_{3}\right): \delta(\mathrm{ppm})=3.44\left(\mathrm{t}, J=6.7 \mathrm{~Hz}, 2 \mathrm{H},-\mathrm{CH}_{2}-\mathrm{CH}_{2}-\mathrm{N}\right), 4.27(\mathrm{t}, J=6.7 \mathrm{~Hz}$, $\left.2 \mathrm{H},-\mathrm{CH}_{2}-\mathrm{CH}_{2}-\mathrm{N}\right), 6.90(\mathrm{~s}, 1 \mathrm{H},-\mathrm{N}-\mathrm{CH}=\mathrm{CH}-\mathrm{N}=), 7.02(\mathrm{~s}, 1 \mathrm{H},-\mathrm{N}-\mathrm{CH}=\mathrm{CH}-\mathrm{N}=), 7.45-7.50(\mathrm{~m}, 6 \mathrm{H}$, -N-CH=N-, Ar-H), 7.68 (d, $J=8.4 \mathrm{~Hz}, 2 \mathrm{H}, \mathrm{Ar}-\mathrm{H}$ ), 7.95 (d, $J=8.4 \mathrm{~Hz}, 2 \mathrm{H}, \mathrm{Ar}-\mathrm{H}) ;{ }^{13} \mathrm{C}-\mathrm{NMR}\left(\mathrm{CDCl}_{3}\right)$ : $\delta 30.9\left(-\mathrm{CH}_{2}-\mathrm{CH}_{2}-\mathrm{N}\right), 43.7\left(-\mathrm{CH}_{2}-\mathrm{CH}_{2}-\mathrm{N}\right), 118.7(-\mathrm{N}-\mathrm{CH}=\mathrm{CH}-\mathrm{N}=), 127.1,127.3,129.1,129.2,130.1$, 130.9, 131.4, $132.8(-\mathrm{N}-\mathrm{CH}=\mathrm{CH}-\mathrm{N}=$, Ar-CH, Ar-C), $136.9(-\mathrm{N}-\mathrm{CH}=\mathrm{N}-), 140.2($ Ar-C $), 162.7(\mathrm{C}=\mathrm{N})$, $163.7(\mathrm{C}=\mathrm{O})$; $\mathrm{MS} m / z(\mathrm{ESI}): 354.1[\mathrm{M}+1]^{+}$.

(E)-3-(1H-Imidazol-1-yl)-1-phenylpropan-1-one O-3-chlorobenzoyl oxime (5k). Yield 61\%; pale yellow viscous oil; IR (KBr): $v\left(\mathrm{~cm}^{-1}\right)$ 3113, $1751(\mathrm{C}=\mathrm{O}), 1654(\mathrm{C}=\mathrm{N}), 1510,1282,739$; ${ }^{1} \mathrm{H}-\mathrm{NMR}$ $\left(\mathrm{DMSO}-d_{6}\right): \delta(\mathrm{ppm})=3.52\left(\right.$ br. s, $\left.2 \mathrm{H},-\mathrm{CH}_{2}-\mathrm{CH}_{2}-\mathrm{N}\right), 4.30$ (br. s, $\left.2 \mathrm{H},-\mathrm{CH}_{2}-\mathrm{CH}_{2}-\mathrm{N}\right), 6.80(\mathrm{~s}, 1 \mathrm{H}$, $-\mathrm{N}-\mathrm{CH}=\mathrm{CH}-\mathrm{N}=), 7.17(\mathrm{~s}, 1 \mathrm{H},-\mathrm{N}-\mathrm{CH}=\mathrm{CH}-\mathrm{N}=), 7.51-7.82(\mathrm{~m}, 8 \mathrm{H},-\mathrm{N}-\mathrm{CH}=\mathrm{N}-, \mathrm{Ar}-\mathrm{H}), 8.00(\mathrm{~d}, \mathrm{~J}=1.5 \mathrm{~Hz}$, $2 \mathrm{H}, \mathrm{Ar}-\mathrm{H}) ;{ }^{13} \mathrm{C}-\mathrm{NMR}\left(\mathrm{DMSO}-d_{6}\right): \delta 30.1\left(-\mathrm{CH}_{2}-\mathrm{CH}_{2}-\mathrm{N}\right), 43.0\left(-\mathrm{CH}_{2}-\mathrm{CH}_{2}-\mathrm{N}\right), 119.3(-\mathrm{N}-\mathrm{CH}=\mathrm{CH}-\mathrm{N}=)$, 
$127.3,128.1,128.5,128.9,130.3,130.9,131.1,132.9,133.6,133.7$ (-N-CH=CH-N=, Ar-CH, Ar-C), $137.1(-\mathrm{N}-\mathrm{CH}=\mathrm{N}-), 161.7(\mathrm{C}=\mathrm{N}), 164.8(\mathrm{C}=\mathrm{O}) ; \mathrm{MS} m / z(\mathrm{ESI}): 354.1[\mathrm{M}]^{+}$.

(E)-3-(1H-Imidazol-1-yl)-1-phenylpropan-1-one O-2-chlorobenzoyl oxime (51). Yield 60\%; white solid mp. 118-120 ${ }^{\circ} \mathrm{C}$ (isopropanol); IR (KBr): $v\left(\mathrm{~cm}^{-1}\right)$ 3054, $1763(\mathrm{C}=\mathrm{O}), 1658(\mathrm{C}=\mathrm{N}), 1640,1511,1265$, 739; ${ }^{1} \mathrm{H}-\mathrm{NMR}\left(\mathrm{DMSO}-d_{6}\right): \delta(\mathrm{ppm})=3.45$ (br. s, $\left.2 \mathrm{H},-\mathrm{CH}_{2}-\mathrm{CH}_{2}-\mathrm{N}\right), 4.25$ (br. s, $2 \mathrm{H},-\mathrm{CH}_{2}-\mathrm{CH}_{2}-\mathrm{N}$ ), $6.80(\mathrm{~s}, 1 \mathrm{H},-\mathrm{N}-\mathrm{CH}=\mathrm{CH}-\mathrm{N}=), 7.08(\mathrm{~s}, 1 \mathrm{H},-\mathrm{N}-\mathrm{CH}=\mathrm{CH}-\mathrm{N}=)$, 7.51-7.67 (m, 7H, -N-CH=N-, Ar-H), 7.75 (d, $J=6.9 \mathrm{~Hz}, 2 \mathrm{H}, \mathrm{Ar}-\mathrm{H}$ ), $7.90(\mathrm{~d}, J=7.2 \mathrm{~Hz}, 1 \mathrm{H}, \mathrm{Ar}-\mathrm{H}) ;{ }^{13} \mathrm{C}-\mathrm{NMR}$ (DMSO- $\left.d_{6}\right): \delta 30.2\left(-\mathrm{CH}_{2}-\mathrm{CH}_{2}-\mathrm{N}\right), 43.0$ $\left(-\mathrm{CH}_{2}-\mathrm{CH}_{2}-\mathrm{N}\right), 119.2(-\mathrm{N}-\mathrm{CH}=\mathrm{CH}-\mathrm{N}=), 127.3,127.6,128.5,128.8,128.9,130.9,131.1,131.3,131.9$, 132.8, $133.7(-\mathrm{N}-\mathrm{CH}=\mathrm{CH}-\mathrm{N}=$, Ar-CH, Ar-C), $137.1(-\mathrm{N}-\mathrm{CH}=\mathrm{N}-), 162.2(\mathrm{C}=\mathrm{N}), 164.6(\mathrm{C}=\mathrm{O}) ; \mathrm{MS} \mathrm{m} / \mathrm{z}$ (ESI): $354.1[\mathrm{M}]^{+}$.

\subsection{Anti-Candida Activity}

\subsubsection{Anti-Candida Agents}

Miconazole was purchased from Sigma-Aldrich Co. (St. Louis, MO, USA) and fluconazole from Shouguang-Fukang Pharmaceutical Ltd. (Shandong, China). The antifungal discs (containing $25 \mu \mathrm{g}$ fluconazole and/or $10 \mu \mathrm{g}$ miconazole) were purchased from ROSCO (Neo-Sensitabs, Taastrup, Denmark).

Dimethyl sulfoxide (100\%) was used to dissolve stock solutions of miconazole, fluconazole and/or the synthesized compounds $\mathbf{4 a}-\mathbf{d}$ and $\mathbf{5 a}-\mathbf{l}$ to obtain an initial concentration of $1000 \mu \mathrm{g} / \mathrm{mL}$. These stock solutions were then diluted to the desired concentration with sterile distilled water. Miconazole and fluconazole antifungal discs were stored at $-80^{\circ} \mathrm{C}$ until used.

\subsubsection{Media}

Liquid RPMI 1640 medium supplemented with L-glutamine was purchased from Sigma-Aldrich Co. (St. Louis, MO, USA) and was added to $2 \%$ sodium bicarbonate and $0.165 \mathrm{M}$ morpholine- propane sulfonic acid (MOPS) from Dojindo Laboratories (Kumamoto, Japan) then adjusted to pH 7.0. Sabouraud Dextrose Agar (SDA) and Brain Heart Infusion Broth (BHI) from Difco Laboratories (Detroit, MI, USA). Potato dextrose agar (PDA) was purchased from Eiken Chemical Co. Ltd. (Tokyo, Japan).

\subsubsection{Organisms}

Two clinical isolates of Candida species were obtained from King Khaled Hospital, Riyadh, Saudi Arabia. One was identified as C. albicans and the other as C. tropicalis. The yeasts were stored at $-70{ }^{\circ} \mathrm{C}$ in BHI with glycerol 5\% until tested.

\subsubsection{Preparation of Inocula}

Preparation of inocula for the broth microdilution testing was performed in accordance with CLSI documents M27-A2 [23] with RPMI 1640 medium. Yeast isolates were subcultured at $35{ }^{\circ} \mathrm{C}$ for $48 \mathrm{~h}$ on PDA plates. Candida cells were then recovered and suspended in $5 \mathrm{~mL}$ of sterile saline. The turbidity of each suspension was adjusted to a $0.5 \mathrm{McFarland}$ standard (corresponding to $1-3 \times 10^{6}$ to $5-3 \times 10^{6} \mathrm{CFU} / \mathrm{mL}$ ) at a wavelength of $530 \mathrm{~nm}$ according to the reported method [23]. Each 
suspension was diluted 1,000-fold with sterile RPMI 1640 medium to give a final inoculum of $1-3 \times 10^{3}$ to $5-3 \times 10^{3} \mathrm{CFU} / \mathrm{mL}$.

\subsubsection{Disk Diffusion Assay}

The disk diffusion assay was performed as described previously [24]. Colonies obtained from the Candida strains under test were suspended in sterile saline and adjusted to a $0.5 \mathrm{McFarland}$ standard (corresponding to $5 \times 10^{6} \mathrm{CFU} / \mathrm{mL}$ ). An aliquot of $100 \mu \mathrm{L}$ of each yeast suspension was spread uniformly onto SDA plates. Six mm Whatmann filter paper disks were impregnated with $1000 \mu \mathrm{g}$ of the synthesized compounds $4 \mathbf{4}-\mathbf{d}$ and $\mathbf{5 a}-\mathbf{l}$ and were allowed to dry. Then they were placed onto the surface of the inoculated agar plates together with the standard antifungal discs which were then incubated at $35^{\circ} \mathrm{C}$. Diameters of inhibition zones were measured at $24 \mathrm{~h}$.

\subsubsection{Antifungal Susceptibility Studies}

The MIC of the reference standards and/or the synthesized compounds $4 \mathbf{4 a}-\mathbf{d}$ and $\mathbf{5 a}-\mathbf{l}$ were determined with a microdilution test (M27-A2 Protocol), according to the reference method of the CLSI. The previously prepared yeast inocula $(100 \mu \mathrm{L})$ were added to each well of 96-well flat-bottom microdilution plates; each well contained $100 \mu \mathrm{L}$ of twofold serial dilutions of the standard or the synthesized compounds $\mathbf{4 a - d}$ and $\mathbf{5 a}-\mathbf{l}$ ranging from $1 \mu \mathrm{g} / \mathrm{mL}$ to $500 \mu \mathrm{g} / \mathrm{mL}$ in RPMI 1640 medium. Readings were measured at $490 \mathrm{~nm}$ with a microplate ELISA reader after each plate was incubated at $35{ }^{\circ} \mathrm{C}$ for $48 \mathrm{~h}$. The MICs for the reference standards and/or the synthesized compounds were determined with $80 \%$ growth inhibition at the end point relative to the turbidity of the growth control.

\section{Conclusions}

Anti-Candida activities of certain new imidazole-containing oximes $\mathbf{4 a}-\mathbf{d}$ and their respective aromatic esters $\mathbf{5 a}-\mathbf{l}$ have been reported. The synthesized compounds $\mathbf{4 a}-\mathbf{d}$ and $\mathbf{5 a}-\mathbf{l}$ exhibited anti-Candida activity better than that of the gold standard antifungal drug, fluconazole. Compound 5j emerged as the most active congener among the all synthesized compounds, being about 3.5 -fold and 300 -fold more potent than miconazole and fluconazole, respectively. Compound $\mathbf{5 j}$ could be considered as a prodrug and could serve as a new lead for anti-Candida agents.

\section{Acknowledgments}

The authors would like to extend their sincere appreciation to the Deanship of Scientific Research at King Saud University for its funding of this research through the Research Group Project no. RGP-VPP-196.

\section{Conflicts of Interests}

The authors have declared that there is no conflict of interests. 


\section{References}

1. Imwidthaya, P.; Poungvarin, N. Cryptococcosis in AIDS. Postgrad. Med. J. 2000, 76, 85-88.

2. Sutton, D.A.; Fothergill, A.W.; Rinaldi, M.G. Guide to Clinically Significant Fungi, 1st ed.; Williams and Wilkins: Baltimore, MD, USA, 1998.

3. Saral, R. Candida and Aspergillus infections in immunocompromised patients: An overview. Rev. Infec. Dis. 1991, 13, 487-492.

4. Odds, F.; Brown, A.J.P.; Gow, N.A.R. Antifungal agents: Mechanisms of action. Trends Microbiol. 2003, 11, 272-279.

5. Joseph-Horne T.; Hollomon, D.W. Molecular mechanisms of azole resistance in fungi. FEMS Microbiol. Lett. 1997, 149, 141-149.

6. Vanden Bossche, H.; Dromer, F.; Improvisi, I.; Lozano-Chiu, M.; Rex, J.H.; Sanglards, D. Antifungal drug resistance in pathogenic fungi. Med. Mycol. 1998, 36, 119-128.

7. Marichal, P.; Vanden Bossche, H. Mechanisms of resistance to azole antifungals. Acta Biochim. Pol. 1995, 42, 509-516.

8. De Luca, L. Naturally occurring and synthetic imidazoles: Their chemistry and their biological activities. Curr. Med. Chem. 2006, 13, 1-23.

9. Pennisi, M.; Antonelli, M. Clinical aspects of invasive candidiasis in critically III patients. Drugs 2009, 69, 21-28.

10. Chen, S.C.; Playford, E.G.; Sorrell, T.C. Antifungal therapy in invasive fungal infections. Curr. Opin. Pharmacol. 2010, 10, 522-530.

11. Wang, W.; Sheng, C.; Che, X.; Ji, H.; Miao, Z.; Yao, J.; Zhang, W. Design, synthesis, and antifungal activity of novel conformationally restricted triazole derivatives. Arch. Pharm. 2009, 342, 732-739.

12. Hamdan, J.S.; Hahn, R.C. Antifungal drugs for systemic mycosis: An overview of mechanism of action and resistance. Anti-Infective Agents Med. Chem. 2006, 5, 403-412.

13. Rossello, A.; Bertini, S.; Lapucci, A.; Macchia, M.; Martinelli, A.; Rapposelli, S.; Herreros, E.; Macchia, B. Synthesis, Antifungal activity, and molecular modeling studies of new inverted oxime ethers of oxiconazole. J. Med. Chem. 2002, 45, 4903-4912.

14. Aboul-Enein, M.N.; El-Azzouny, A.A.; Attia, M.I.; Saleh, O.A.; Kansoh, A.L. Synthesis and Anti-Candida Potential of Certain Novel 1-[(3-Substituted-3-phenyl)propyl]-1H-imidazoles. Arch. Pharm. 2011, 344, 794-801.

15. Roman, G.; Mares, M.; Nastasa, V. A novel antifungal agent with broad spectrum: 1-(4-Biphenylyl)-3-(1H-imidazol-1-yl)-1-propanone. Arch. Pharm. 2013, 346, 110-118.

16. Walker, K.A.; Hirschfeld, D.R.; Marx, M. Antimycotic imidazoles. 2. Synthesis and antifungal properties of esters of 1-[2-hydroxy(mercapto)-2-phenylethyl]-1H-imidazoles. J. Med. Chem. 1978, 21, 1335-1338.

17. Fun, H.-K.; Quah, C.K.; Attia, M.I.; Almutairi, M.S.; Ghoneim, S.W. (E)-N-[3-(Imidazol-1-yl)-1phenylpropylidene]hydroxylamine. Acta Crystallogr. E-Struct. Rep. 2012, E68, o627.

18. Pfaller, M.A.; Andes, D.; Diekema, D.J.; Espinel-Ingroff, A.; Sheehan, D. Wild-type MIC distributions, epidemiological cutoff values and species-specific clinical breakpoints for fluconazole and Candida: Time for harmonization of CLSI and EUCAST broth microdilution methods. Drug Resist. Update. 2010, 13, 6180-6195. 
19. De Vita, D.; Scipione, L.; Tortorella, S.; Mellini, P.; Di Rienzo, B.; Simonetti, G.; D’Auria, F.D.; Panella, S.; Cirilli, R.; Di Santo, R.; et al. Synthesis and antifungal activity of a new series of 2-(1H-imidazol-1-yl)-1-phenylethanol derivatives. Eur. J. Med. Chem. 2012, 49, 334-342.

20. Wan, J.; Peng, Z.-Z.; Li, X.-M.; Ouyang, P.-K.; Zhang, S.-S. 3-(1H-Imidazol-1-yl)-1-(4methoxyphenyl)propan-1-one. Acta Crystallogr. E-Struct. Rep. 2005, E 61, o2585-o2586.

21. Selvamurugan, V.; Aidhen, I.S. Simple Synthetic Equivalents for the $\beta-(N, N-$ Disubstituted)ethylamino Acyl Cation Synthon and their Applications. Synthesis 2001, 2239-2246.

22. Attia, M.I.; Ghabbour, H.A.; Almutairi, M.S.; Ghoneim, S.W.; Abdel-Aziz, H.A.; Fun, H.-K. Synthesis and X-ray crystal structure of (1E)-1-(4-chlorophenyl)- $N$-hydroxy-3-(1H-imidazol-1yl)propan-1-imine. J. Chem. 2013, doi:10.1155/2013/418601.

23. Clinical and Laboratory Standards Institute (CLSI). Reference method for broth dilution antifungal susceptibility testing of yeasts, In Approved Standard M27-A2, 2nd ed.; CLSI: Villanova, PA, USA, 2002.

24. Clinical and Laboratory Standards Institute (CLSI). Performance Standards for Antimicrobial Disk Susceptibility Tests, In Approved Standard, M2-A8, 8th ed.; CLSI: Wayne, PA, USA, 2005.

Sample Availability: Contact the authors.

(C) 2013 by the authors; licensee MDPI, Basel, Switzerland. This article is an open access article distributed under the terms and conditions of the Creative Commons Attribution license (http://creativecommons.org/licenses/by/3.0/). 